\title{
Comparison of Different Doses of Petroleum Ether Extracts of Sphaeranthus indicus Linn Against Dutasteride on Testosterone and PSA in Murine Model of Benign Prostatic Hyperplasia
}

${ }^{1}$ Sabiha Erum Khan, ${ }^{2}$ Bisma Fatima Aslam, ${ }^{1}$ Saadia Shahzad Alam

${ }^{1}$ Department of Pharmacology, Shaikh Zayed Medical Complex, Lahore

${ }^{2}$ Department of Pharmacology, AzraNaheed Medical College, Lahore

\begin{abstract}
Introduction: Benign Prostatic Hyperplasia (BPH) is the most common health problem of male elderly population resulting in lower urinary tract symptoms (LUTS), characterized by frequency, urgency, hesitancy, nocturia, dysuria and incomplete voiding. Aims \& Objectives: To compare the different doses of petroleum ether extracts of Sphaeranthus indicus Linn (SiP) against Dutasteride, on hormonal parameters (serum testosterone and PSA) in testosterone induced BPH in albino mice. Place and Duration of study: This experimental study was conducted at the Animal House of PGMI, Lahore for 6 months. Material \& Methods: Thirty-six healthy adult male mice, divided into 6 groups, were administered testosterone, different doses of petroleum ether extract $S i L$ extracts $(S I P)$ and dutasteride. Animals in group 1, taken as control, were given $0.1 \mathrm{ml}$ corn oil daily subcutaneously for 28 days. The animals in the remaining 5 groups (\# 2-6) were given $3 \mathrm{mg} / \mathrm{kg}$ body weight testosterone dissolved in corn oil subcutaneously for 28 days, to induce BPH. The animals in group 3 were given $20 \mathrm{mg} / \mathrm{kg}$ /day Dutasteride orally for 28 days. Animals in groups 4-6 were given $25,50 \mathrm{mg}$ and $75 \mathrm{mg} / \mathrm{kg}$ body weight petroleum ether extract $(S I P)$ orally for 28 days. Blood samples were drawn on day 0,14 and 28 for the estimation of serum testosterone and serum PSA, by ELISA technique. Data was analyzed using SPSS Version 20.0. Comparison (between groups at baseline, day14 and day 28)was done by using one-way ANOVA and Post Hoc Tukey's test Results: Decrease in PSA level and increase in serum testosterone supports the alpha reductase inhibiting activity of $\mathrm{SiP}$, in a dose dependent manner, in testosterone induced BPH. SI petroleum ether extract $75 \mathrm{mg} / \mathrm{kg}$ exhibited efficacy similar to that of dutasteride. Conclusion: Sphaeranthus indicus Linn $(\mathrm{SiP})$ has shown efficacy equal to that of dutasteride in attenuating the testosterone induced $\mathrm{BPH}$, in albino mice.
\end{abstract}

Key words: Benign prostatic hyperplasia, testosterone, prostate specific antigen, Dutasteride, Sphaeranthus indicus Linn (SIL), Petroleum ether extract of Sphaeranthus indicus Linn (SiP).

\section{INTRODUCTION}

"I do not need you to remind me of my age.

I have a bladder to do that for me". (Stephen Fry—author of "The Fry Chronicles")

B enign prostatic hyperplasia (BPH) is the most common, although benign, bothersome malady causing significant urinary symptoms in the male elderly population. ${ }^{1}$ Based on histology, the term refers to proliferation of smooth muscles and epithelial cells situated in the transition zone of the gland. $^{2}$

$\mathrm{BPH}$ could progress unchecked, if not managed rationally, leading to Lower Urinary Tract
Symptoms (LUTS) manifested by weak urinary stream, hesitancy, incomplete voiding and irritative symptoms including frequency, urgency, nocturia and dysuria. ${ }^{3}$ Incomplete voiding results in stasis of residual urine with an increased risk of recurrent urinary infections. Chronic urinary retention may result in renal failure in some patients. ${ }^{4}$ Generally, it is not a life-threatening condition. ${ }^{5}$ However, it is well known to have significant detrimental effect on a patient's quality of life (QoL). ${ }^{6}$

Whereas the incidence is on increase due to an increase in average life span, the threat of BPH is hanging over most of elderly men as the "Sword of Damocles". ${ }^{7}$ It affects 50 percent men between 51 and 60 years and about 80 percent in their eighties. ${ }^{8}$ 
The etiology is not clearly understood. ${ }^{9}$ However, the development of $\mathrm{BPH}$ is associated with the presence of testicular androgens during prostate development and growing age. ${ }^{10}$ The major portion of Testosterone, in men, is produced by Leydig cells of the testes but also, to a lesser extent, by adrenal cortex. In the body tissue, the testosterone is converted into Dihydrotestosterone (DHT) which is more potent and plays an important role in the development of prostate. However, the presence of DHT, in adulthood, could be injurious as it would result in unchecked growth of the gland. ${ }^{11}$ The physiologically well characterized 5AR substrate, the androgen testosterone and its more potent metabolite DHT are essential hormones responsible for male phenotypic sexual differentiation and maturation through their actions at the androgen receptor". ${ }^{12}$

PSA is chemically a serine protease, produced primarily by the glands in the transition zone and is androgen dependent. The highest amount of PSA is found in these minal fluid; some amount of PSA escapes the prostate and could be detected in the serum. The rising levels of PSA in serum are associated with prostate cancer, however the levels may also rise in BPH. The normal value for total PSA in human blood is $4 \mathrm{ng} / \mathrm{mL}$. When between 410 , it indicates possibility of $\mathrm{BPH}$ or cancer. The normal value of PSA levels in mice is 0.14$0.86 \mathrm{ng} / \mathrm{ml}^{14}$

Alpha blockers and 5- alpha reductase inhibitors are the two FDA approved treatment options. Administration of a 5- alpha reductase inhibitor (Dutasteride and Finasteride), offers rapid and sustained inhibition of DHT and is therefore the major treatment for $\mathrm{BPH}$, at the present. The patients are at risk of acquiring drug related problems (DRPs), notably dizziness and orthostatic hypotension in case of alpha blockers and sexual dysfunction and gynecomastia by 5 - alpha reductase inhibitors. ${ }^{15}$

Sphaeranthus indicus Linn (gorakmundi) which literally means round flower, in Greek, is a medicinal plant fascinating healthcare provider since centuries. It is an indigenous herb of South Asians being in use in Ayurvedic pharmacopeia, for many ailments. It grows frequently both in cultivated and un-cultivated lands, from sea level to $1200 \mathrm{~m}$ altitude, in Indian sub-continent, Malaysia, China, Africa and Australia. ${ }^{16}$ It is a spreading aromatic plant (becoming odorless on long standing) with spreading glandular stem and branches with purple or pink flowers. ${ }^{17}$

The phytochemical investigations of the plant revealed the presence of ${ }^{17}$ :
- an alkaloid "Spaeranthine"

- a novel "Flavonoid C-glycoside

- Stigmasterol and B-sitosterol

- Bicyclic Sesquiterpene from petroleum extract

Although the efficacy of this medicinal plant in BPH was postulated earlier, the first published study, on its potential use in $\mathrm{BPH}$, was conducted in India, in 2011, by Nahata and Vinod Kumar Dixit. They induced prostatic hyperplasia, in Albino rats, by giving them Testosterone. The administration of SiL was found to attenuate the action of Testosterone. ${ }^{18}$ To the best awareness of authors, no authentic published work is available on its potential use in $\mathrm{BPH}$, in Pakistan.

Whereas Nahata and Dixit used Finasteride as positive control, we opted Dutasteride instead. It is already known that Finasteride (selective $5 \alpha-$ reductase inhibitor) achieves $70 \%$ suppression which in case of Dutasteride (from non-selective group) reaches up to $94.8 \% .^{19}$

\section{MATERIAL AND METHODS}

\section{Animals:}

36 adult male mice of Balb $\mathrm{C}$ species, weighing 20$30 \mathrm{gm}$, were purchased and housed in University of Health Sciences, Lahore. They were kept in standard polyprolene cages, at controlled room temperature of $25+10^{\circ} \mathrm{C}$ and relative humidity 60 $70 \%$. Six groups of 6 animals each, were used for the experiment. Duration of study was total of 28 days.

Testosterone Propionate (Tesvot $250 \mathrm{mg}$ ) injections were purchased from local pharmacy. All groups (except the control one) received $3 \mathrm{mg} / \mathrm{kg}$ body weight Testosterone Propionate subcutaneously for 28 days, to induce $\mathrm{BPH} .{ }^{20}$

Dutasteride (Avodart $0.5 \mathrm{mg}$ ) tablets were purchased from the local pharmacy. Animals in group 3 were given $20 \mathrm{mg} / \mathrm{kg} /$ day Dutasteride orally for 28 days.

Mouse testosterone Elisa Kits and Mouse PSA Elisa kits were purchased from Glory Science Limited USA. Petroleum Ether was purchased from Merck Pharmaceuticals.

\section{Plant Material:}

Flower heads of SiL were collected from Lahore area. They were identified and authenticated from the herbarium maintained by the Department of Botany of University of the Punjab Lahore. They were kept at normal room temperature. Petroleum ether was prepared in the Chemistry Department of PCSIR Laboratory Lahore. 


\section{Preparation of Petroleum Ether Extract:}

$500 \mathrm{gms}$ of powdered flower heads of $\mathrm{SiL}$ were dipped in 2L petroleum ether, kept for $48 \mathrm{hrs}$ with periodic shaking and left for half an hour to settle down. It was then filtered in a big flask using Whatman's filter paper and glass funnel. The filtrate evaporated in rotary evaporator until all the petroleum ether was removed and dark greenish yellow waxy mass was obtained. ${ }^{18}$ From $500 \mathrm{~g}$ herb, the extract obtained was $14 \mathrm{gm}$ ( $2.8 \%$ yield $)$.

Animal Grouping:

Animals in group 1 (control group) were given $0.1 \mathrm{ml}$ corn oil daily subcutaneously for 28 days.

The animals in the remaining 5 groups (2-5 groups) were given $3 \mathrm{mg} / \mathrm{kg}$ body weight of testosterone (containing $0.075 \mathrm{mg}$ testosterone) dissolved in $0.1 \mathrm{ml}$ of corn oil subcutaneously for 28 days.

Animals in group 3 were given $20 \mathrm{mg} / \mathrm{kg} /$ day Dutasteride orally for 28 days.

Those in group 4, 5 and 6 received $25 \mathrm{mg}, 50 \mathrm{mg}$ and $75 \mathrm{mg} / \mathrm{kg}$ body weight $\mathrm{SiP}$ extract orally for 28 days.

\section{Statistical analysis:}

Data was analyzed by SPSS Version 20.0. The data for serum testosterone and serum PSA levels obtained by using mean \pm sd. Comparison (between groups at baseline, day14 and day 28)was done by using one-way ANOVA and Post Hoc Tukey's Test. Lettering was assigned on the basis of Tukey's Test. Different letters in superscript represented significant difference from each other and those having common letters were non significant with $p$ value 0.05 . Cluster bar diagrams were made to give visual difference between groups at each reading time and error bars were used to show the standard deviations. P-value $\leq 0.05$ was considered statistically significant.

\section{RESULTS}

The mean serum testosterone levels at baseline were 1.55 to 1.59 and had no significant difference (pvalue 0.271 ). At day 14 the group 6 had highest level, significantly different from all other groups, followed by group 3, 5 and 4 respectively. The group 1 and 2 had no significant difference from each other on day 14 but had significantly lower mean testosterone levels as compared to all other groups. On day 28 the testosterone levels increased in all groups as compared to day 14 and group $3 \mathrm{had}$ the highest mean level of $10.48 \mathrm{ng} / \mathrm{ml}$, non significantly different from group 6 but significantly higher than all other groups. The group 2 also had significantly higher level as compared to group 1, but significantly lower than group 4 and 5. (Fig-1)

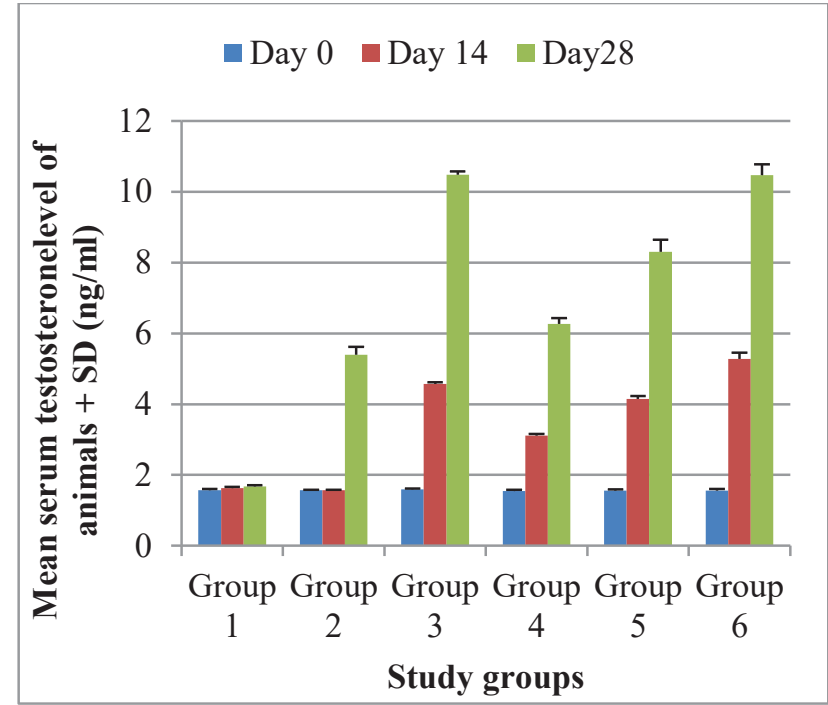

Fig-1: Cluster bar diagram presenting mean serum testosterone levels for six study groups (error bars presenting standard deviation)

The mean serum PSA levels, ranging between 0.22 and $0.25 \mathrm{ng} / \mathrm{ml}$ at base line with standard deviations ranging between 0.02 and 0.04 , were insignificantly different with $\mathrm{p}$-value 0.651 . On day 14 the mean levels in all groups (except group1) rose significantly, the highest being in group 2. Groups 3,5 and 6 had no significant difference from each other, either on day 14 or day 28. Group 4 had significantly higher level in comparison to other groups but lower than group 2. The same was the difference on day 28 , though the mean levels in all groups were higher as compared to day 14. (Table2, Fig-2)

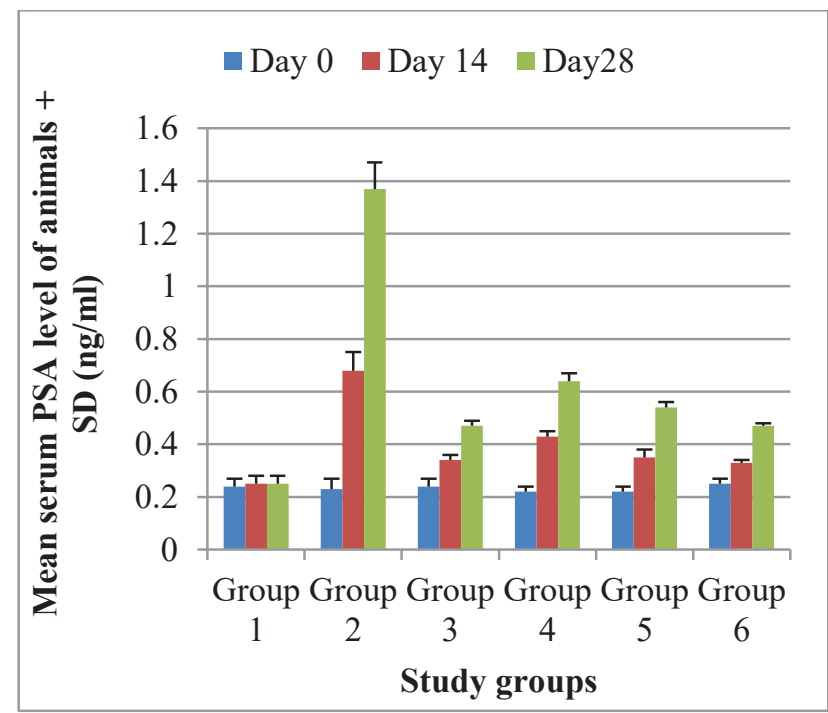

Fig-2: Cluster bar diagram presenting mean serum PSA levels for six study groups (error bars presenting standard deviation) 


\section{DISCUSSION}

$\mathrm{BPH}$ is a progressive age-related health problem of elderly men. It is clinically characterized by prostatic enlargement and resultant LUTS causing significant detrimental effects on QoL of the life of the patients. ${ }^{1,6}$ It is not a premalignant condition and has anetiology different from prostatic cancer. A variety of growth factors and inflammatory process could contribute to the causation. ${ }^{9}$

Although many medical and surgical treatment options are available, the problems of the patients remain unresolved in a significant number of cases. The medical therapy does not work for everyone. The drug related problems have a serious impact. The surgical intervention may, in some cases, worsen the condition. The immediate post-operative complications include bacterial infection (up to $15 \%$ ), impotence (upto $17 \%$ ) and retrograde ejaculation (upto 77\%). However, the incidence of actual post-operative complications, as concluded by Stefanie Petrou Binder, is higher than that reported in literature. ${ }^{22}$

Phytotherapy, as a new treatment option for $\mathrm{BPH}$, is gaining popularity on global level. $\mathrm{SiL}$ is in use in Ayurvedic System of traditional medicine, for many ailments. ${ }^{23}$ It is an ingredient of "Prostabliss" which is said to have beneficial effects on BPH. ${ }^{14}$

The present study was conducted to assess the efficacy of various doses of petroleum ether extracts of this herb in comparison to dutasteride in testosterone induced prostatic hyperplasia in albino mice. Testosterone levels were measured in this study on day 0,14 and 28 as a marker of 5 alpha reductase inhibition. All the groups (except the control one) showed an elevation of testosterone levels because of exogenous testosterone treatment. The effect on group 3 (Testosterone+Dutasteride) was quite similar to that in group 6 (Testosterone+ $\mathrm{SiP}$ ) manifesting an increment of $572.5 \%$ in serum testosterone level. Results show that Group 3 had significantly higher serum testosterone level than all the groups except 6 with a p-values $<0.05$. These findings support the alpha reductase inhibitory effect of SiL. ${ }^{25}$

At day 28, the average mean serum PSA level of group 1 was $0.25 \mathrm{ng} / \mathrm{ml}$ and that for group 2 was $1.37 \mathrm{ng} / \mathrm{ml}$. The comparatively highest level in group 2 (testosterone alone) could be explained because of the resultant prostatic hyperplasia. Group 1 had significantly lower levels as compared to all other groups while group 2 showed significantly higher PSA levels as compared to all other groups with pvalues $<0.05$. It shows that the testosterone opposing effect of dutasteride was comparable with
SiP $50 \mathrm{mg} / \mathrm{kg}$ and $\mathrm{SiP} 75 \mathrm{mg} / \mathrm{kg}$ body weight. The only available comparable study (Nahata et al) also showed a decrease in serum PSA by beta sitosterol of SiL. ${ }^{18}$

A large multi-centered study is required to further evaluate the alpha reductase inhibitory effect of the fascinating herb. The results of the present study, if confirmed on a large scale, would, most hopefully, bring a revolutionary change in the management of $\mathrm{BPH}$ and the patients would be saved from the injurious untoward effects of the presently available therapeutic regime. This joint venture of the pharmacologists, urologists and pharmacists is the need of the day.

\section{CONCLUSION}

In conclusion, this fascinating herb has shown efficacy equal to that of dutasteride in attenuating the testosterone induced BPH in albino mice. The results suggest that petroleum ether extracts of $\mathrm{SiL}$ prevented prostatic hyperplasia significantly in a dose dependent manner. The best activity was exhibited by SiP $75 \mathrm{mg} / \mathrm{kg}$ body weight.

\section{REFERENCES}

1. Auffenberg GB, Helfand B, Mc Vary KT. Established Medical Therapy for Benign Prostatic Hyperplasia-UrolClin North Am. 2009; 36(4):443-459.

2. Craft J, Gordon $\mathrm{C}$, Adriana $\mathrm{P}$ et al. Understanding Pathophysiology. ANZ Adaptation-Elsvier Health Sciences April 2013.

3. Wang JY, Liu M, Zhang YG. Relationship between Lower Urinary Tract Symptoms and Objective Measures of Benign Prostatic Hyperplasia: A Chinese Survey-China Med J. 2008; 121(20):2042-2045.

4. Timothy JW. Benign Prostatic Hyperplasia. BMJ. 2008; 336: 146.

5. deReijke TM, Klarskov P. Comparative efficacy of two a1-adrenoceptor antagonists, Doxazocin and Alfuzocin in patients with lower urinary tract symptoms from benign prostatic enlargement. BJU Int. 2004; 93:757-762.

6. Bruskewitz RC. Quality of life and sexual function in patients with Benign Prostatic Hyperplasia. Rev Urol. 2003; 5(2):72-80.

7. Vision VIP. EN. International People GroupBiologically Active Food Suppl -Prostate

8. Napalkov P, Maisonneuve P, Boyle P. Worldwide patterns of prevalence and mortality from benign prostatic hyperplasia. Urology. 1995; 46(3):41-46. 
9. Lepor H. Pathophysiology, epidemiology and natural history of benign prostatic hyperplasia. Rev Urol. 2004; 6(suppl 9):s3-s10.

10. Briganti A, Capitanio U, Suardi N. et al. Benign Prostatic Hyperplasia and its Aetiologies. EurUrolSuppl 8. 2009; 865-871.

11. Carson C, Rittmaster R. The Role of Dihydrotestosterone in Benign Prostate Hyperplasia. Urology. 2003; 61(4 suppl):2-7.

12. Nef S, Parada LF. Hormones in male sexual development. Genes Dev. 2000; 14:3075-3086.

13. Balk SP, Ko Y-J, Bubley GT. Biology of Prostate Specific Antigen. J ClinOncol. 2003; 21:383-391.

14. Kindblom J. Role of Prolactin in the Prostate Gland: Studies in Transgenic Mouse Model. PhD Thesis Goteborg University. Goteborg2003

15. Huri HZ, Sulaiman CZ. Drug related Problems in Patients with Benign Prostatic Hyperplasia: A Cross-sectional Retrospective Study. PLOS/ONE. 2014; 9(1).

16. Ramachandran S. Review on Sphaeranthus indicus (Kottaikkarantai). Pharmacogonosy Review. 2013; Jul-Dec 7(14):157-169.

17. Chakraborty AK, Behera M, Roy H, Rambhade S. Sphaerathus indicus Linn-A Phytophamacological Review. Int J Drug Farmulation Research. 2010; vol 1(3):113-133.

18. Nahata A, Dixit VK. Sphaeranthus indicus attenuates Testosterone Induced prostatic hypertrophy in Albino Rats. Phytotherapy Research. John Willey and Sons Ltd. 2011.

19. Nickel JC. Comparison of clinical trials with Finestride and Dutasteride. Reviews in Urology. 2004; 6 supp19: s31-s39.

20. Gleave ME, Hsieh JT, Wu HC et al. Serum Prostate Specific Antigen Levels in Mice Bearing Human Prostate LNCaP Tumors are determined by Tumors Volume and Endocrine and Growth Factors. Cancer Res.1992;1598-1605

21. Urology Care Foundation. BPH: Surgical Management. Urology A-Z. July 2013.
22. Binder SP. BPH surgery complications underestimated in clinical trials. Urology Times June 01, 2012.

23. Suter A, Saller R, Riedi E et al. Improving BPH Symptoms and Sexual Dysfunctions with a Saw Palmetto preparation? Results from a Pilot Trial. Phytother Res. 2013; 27(2):218-226.

24. MHFW (Ministry of Health and Family Welfare). The Ayurvedic Pharmacopea of India -1 st edition part 1 vol 3. The Controller of Publications, New Delhi 2001.

25. Nahata A, Sexena A, Suri N Dixit VK. Sphaeranthus indicus induces Apoptosis through mitochondrial dependent pathway in HL-60 cells and exerts cytotoxic potential on several human cancer cell lines. Integ Cancer Therapy. August 22, 2012.

\section{The Authors:}

Dr. Sabiha Erum Khan

P.G. Trainee,

Department of Pharmacology\& Therapeutics, Shaikh Zayed Medical Complex, Lahore.

Dr. Bisma Fatima Aslam

Demonstrator,

Department of Pharmacology \& Therapeutics, Azra Naheed Medical College, Lahore.

Prof. Saadia Shahzad Alam

HOD, Pharmacology \& Therapeutics,

Shaikh Zayed Medical Complex, Lahore.

\section{Corresponding Author:}

Dr. Sabiha Erum Khan

P.G. Trainee,

Department of Pharmacology\& Therapeutics, Shaikh Zayed Medical Complex, Lahore.

E-mail: drsabihaerum@gmail.com 